\title{
Dynamic Capital Structure Adjustment: WHICH ESTIMATOR YIELDS CONSISTENT AND EFFICIENT ESTIMATES?
}

\author{
Vusani Moyo \\ University of Venda \\ vusani.moyo@univen.ac.za
}

Received: March 2015

Accepted: September 2015

\begin{abstract}
The partial adjustment model is key to a number of corporate finance research areas. The model is by its nature an autoregressive-distributed lag model that is characterised by heterogeneity among individuals and autocorrelation due to the presence of the lagged dependent variable. Finding a suitable estimator to fit the model can be challenging, as the existing estimators differ significantly in their consistency and bias. This study used data drawn from 143 non-financial firms listed on the Johannesburg Stock Exchange (JSE) to test for the consistency and efficiency of the leading partial adjustment model estimators. The study results confirm the bias-corrected least squares dummy variable (LSDVC) initialised by the system generalised method of moments (GMM) estimator, the random effects Tobit estimator and the system GMM estimator as the most suitable estimators for the partial adjustment model. The difference GMM estimator and the Anderson-Hsiao instrumental variables estimator are inconsistent and biased in the context of the partial adjustment model.
\end{abstract}

Keywords

Partial adjustment; speed of adjustment; system GMM, difference GMM, instrumental variables; random effects Tobit.

Prof V Moyo is an associate professor in the Department of Accounting and Auditing, University of Venda, South Africa. 


\section{INTRODUCTION}

The dynamic trade-off theory of Fischer, Heinkel and Zechner (1989) has emerged as one of the leading capital structure theories that attempt to explain the observed financing behaviour of firms. Hovakimian, Opler and Titman (2002:25) concede that this theory is more relevant than the traditional static trade-off theory, which states that firms have static leverage ratios. The dynamic trade-off theory contends that, even if firms have target leverage ratios, these are rarely maintained. The observed leverage ratios fluctuate around the optimal target within an acceptable range. The dynamic leverage ratios derive from the time-variant firm-specific variables of profitability, retention rate, distribution policies, firm investment programme, available financing sources and share prices (Hovakimian, Opler \& Titman, 2001:1). According to the definition of the market-to-debt leverage ratio, changes in these variables would automatically trigger a change in the firm's leverage ratio.

The target deviation spread, which is defined as the difference between the observed current leverage and the theoretical optimal leverage, can be eliminated through mechanical meanreversion and financing means (Chen \& Zhao, 2007; and Hovakimian et al., 2001:22). Of interest to capital structure research is the elimination of the deviation spread through financing means. The deviation spread is a function of target deviation and adjustment costs. The question arises: Do firms actively rebalance their capital structures towards the target leverage? According to Xu (2007:5), a firm will readily adjust if the target deviation costs exceed the target adjustment costs. Thus, the active adjustment towards a target debt ratio assumes a perfect capital market, which assumes zero target adjustment costs. Flannery and Rangan (2006:472) contend that, in cases where the target adjustment costs are zero, firms will frequently and fully adjust to their chosen target ratios. In the real world, markets are characterised by imperfections, with firms facing information asymmetries, transaction costs and adjustment costs which outweigh the optimal target deviation costs. These costs force the firms to operate at suboptimal leverage ratios, with infrequent and partial adjustment of their capital structures towards their predetermined optimal leverage ratios (Leary \& Roberts, 2005; and Oztekin \& Flannery 2012:89). The partial adjustment process is explained by the partial adjustment model, which also infers the firm's speed of adjustment towards the optimal target leverage.

The traditional target leverage adjustment tests were initiated by Taggart (1977) and revised by Auerbach (1985). These tests were further improved by Fama and French (2002) and Flannery and Rangan (2006). The modern target leverage adjustment model is a dynamic first-order partial adjustment model whose regressors are the first lag of leverage, a vector of core traditional firmspecific determinants of leverage and the standard error term. The error term is made up of the stochastic unobservable individual-specific time-invariant effect and the time-variant remainder of the disturbance term. The core traditional firm-specific determinants of leverage are those specified in the Frank and Goyal (2009) standard model; these are asset tangibility, profitability, growth rate and firm size.

The partial adjustment model is, by construction, an autoregressive-distributed lag model, which is characterised by heterogeneity amongst individuals and autocorrelation due to the presence of the lagged dependent variable. The lagged explanatory variable is correlated with the error term. Furthermore, in capital structure research, panel data sample sizes are typically 'large number of firms $(\mathrm{N})$ and short time period $(\mathrm{T})$ ' and the dependable variable is fractional in nature, occurring between 0 and 1 . The main challenge faced by researchers in capital structure is that of 
finding a suitable dynamic panel data model estimator that is consistent, unbiased and efficient in the presence of these possible statistical errors.

A number of estimators have been proposed and applied. The leading dynamic panel data model estimators that have been used in the past studies include the Anderson-Hsiao instrumental variables estimator (Dang, 2013; Huang \& Ritter, 2009; and Verbeek, 2012); the difference GMM estimator (Drobetz \& Wanzeried, 2006:948; Mukherjee \& Mahakud, 2012; Pian, Tian \& Wirjanto, 2009; and Ramjee \& Gwatidzo, 2012); the system GMM estimator (Antoniou, Guney \& Paudyal, 2008; Flannery \& Hankins, 2013; Hovakimian \& Li, 2011; and Moyo, Wolmarans \& Brümmer, 2013); and the random effects Tobit estimator (Elsas \& Florysiak, 2011; Elsas \& Florysiak, 2013; and Moyo et al., 2013). Bruno (2005a and b) proposed the use of the LSDVC estimator, which he claims outperforms the Anderson-Hsiao instrumental variables estimator, the difference GMM estimator and the system GMM estimator in a dynamic unbalanced panel data model with a small number of individuals and finite time periods. All these leading estimators differ in their robustness and their susceptibility to possible model misspecification errors arising from differences in panel sizes and balance, heteroskedasticity and autocorrelation.

The question that persistently confronts researchers in capital structure is: Which of these linear dynamic panel data model estimators are consistent, are the least biased, and are efficient in the context of a partial adjustment model? This paper tests for the consistency and efficiency of these leading estimators. The study applied these estimators in estimating the target speed of adjustment of seven different panel datasets drawn from a sample of 143 non-financial companies listed on the JSE during the period 2003-2012. The results of the study confirm that the LSDVC estimator with the bias correction initialised by the Blundell and Bond estimator, the random effects Tobit estimator and the one-step system GMM estimator have the lowest standard deviations for speed of adjustment estimates, and therefore they are the most consistent estimators for the partial adjustment model in the context of a small $\mathrm{N}$ and finite panel data samples. These estimators are robust to the possible dynamic panel statistical errors. The difference GMM and the Anderson-Hsiao estimator are both unsuitable, as they are upwardsbiased in the context of a linear dynamic panel data model.

The remainder of the article proceeds as follows: the review of related literature and the development of hypotheses are discussed in section 2. Section 3 describes the research methodology and data used in the study. The summary statistics and empirical results of the study are presented and discussed in section 4. Lastly, the conclusions, managerial implications, limitations of the study, and recommendations for future research are discussed in section 5 .

\section{LITERATURE REVIEW AND HYPOTHESES DEVELOPMENT}

\subsection{The dynamic linear model}

The standard linear first-order dynamic panel data model strictly contains exogenous explanatory variables, lag of the dependent variable and additive unobserved individual effects (Baltagi, 2008:147). The model has the form:

$$
y_{i, t+1}=\gamma y_{i, t}+\beta x_{i, t+1}^{\prime}+\varepsilon_{i, t+1} \quad i=1, \ldots, N \quad t=1, \ldots, T
$$

where $\gamma$ is a scalar, $x_{i, t+1}^{\prime}$ is $1 \times k$ and $\beta$ is $k \times 1$ and $\varepsilon_{i, t+1}$ is the error term. The model assumes that $\varepsilon_{i, t+1}$ follows a one-way error component model: 


$$
\varepsilon_{i, t+1}=\mu_{i}+u_{i, t+1}
$$

where $\mu_{i}$ denotes the unobservable individual-specific time-invariant effect, which allows for heterogeneity in the means of the $y_{i, t+1}$ series across the individuals, and $u_{i, t+1}$ denotes the timevariant remainder of the disturbance term. Also, $\mu_{i}$ is treated as being stochastic, and the disturbances, $u_{i, t+1}$, are assumed to be serially correlated. In this model, $\mu_{i} \sim I D D\left(0, \sigma_{\mu}^{2}\right)$ and $u_{i, t+1} \sim I D D\left(0, \sigma_{u}^{2}\right)$ are each independent. Thus the model can also be expressed as:

$$
y_{i, t+1}=\delta y_{i, t}+\beta x_{i, t+1}^{\prime}+\mu_{i}+u_{i, t+1} \quad i=1, \ldots, N \quad t=1, \ldots, T
$$

This dynamic panel data model is characterised by autocorrelation due to the presence of the lagged dependent variable and heterogeneity among individuals. Furthermore, since $y_{i, t+1}=$ $f\left(\mu_{i}\right)$, it follows that $y_{i, t}=f\left(\mu_{i}\right)$, and it is therefore correlated with the error term. In cases where endogenous covariates are included, the extended first-order dynamic panel data model is stated as follows:

$$
y_{i, t+1}=\sum_{j=1}^{p} \alpha_{j} y_{i, t-j}+x_{i, t+1} \beta_{1}+w_{i, t+1} \beta_{2}+\mu_{i}+u_{i, t+1} \quad i=1, \ldots, N \quad t=1, \ldots, T_{i}
$$

where $\alpha_{j}$ are $p$ parameters to be estimated; $x_{i, t+1}$ is a $1 \times k_{1}$ vector of strictly exogenous covariates; $\beta_{1}$ is a $k_{1} \times 1$ vector of parameters to be estimated; $w_{i, t+1}$ is a $1 \times k_{2}$ vector of predetermined and endogenous covariates; and $\beta_{2}$ is a $k_{2} \times 1$ vector of parameters to be estimated.

\subsection{The general partial adjustment model}

The standard partial adjustment model given by Chambers (1996:21) derives from the dynamic model, and it consists of two parts. One part is the static part, which describes how the desired target of $y_{i, t}$ which is $y_{i, t}^{*}$, is determined:

$$
y_{i, t+1}^{*}=\gamma x_{i, t+1}+u_{i, t+1}
$$

The other part is the dynamic partial adjustment model:

$$
y_{i, t+1}-y_{i, t}=\lambda\left(y_{i, t+1}^{*}-y_{i, t}\right)+e_{t+1}, \quad 0<\lambda<1
$$

That is:

$$
y_{i, t+1}=\lambda y_{i, t+1}^{*}+(1-\lambda) y_{i, t}+e_{i, t+1}
$$

where $u_{i, t+1}$ and $e_{i, t+1}$ are independent white noise processes with zero means and variances $\sigma_{u}^{2}$ and $\sigma_{e}^{2}$ respectively.

Substituting $y_{i, t+1}^{*}$ into equation 7 yields the one-step partial adjustment model:

$$
y_{i, t+1}=\gamma_{0} \lambda+(1-\lambda) y_{i, t}+\lambda \gamma_{1} x_{i, t+1}+\lambda u_{i, t+1}
$$

This is an autoregressive-distributed lag model, which can be estimated as:

$$
y_{i, t+1}=\beta_{0}+\beta_{1} y_{i, t}+\beta_{2} x_{i, t+1}+\beta_{3} x_{i, t}+\varepsilon_{i, t+1}
$$

where $\varepsilon_{i, t+1}=\mu_{i}+u_{i, t+1}$. This can also be expressed as: 


$$
E\left(\mu_{i}\right)=E\left(u_{i, t+1}\right)=E\left(\mu_{i} u_{i, t+1}\right)=0
$$

This model resembles the dynamic panel data model and, as such, it is also characterised by autocorrelation and heterogeneity. If the partial adjustment process occurred, then the following restriction would be imposed:

$\beta_{3}=0$

In addition, the estimates of the parameters are defined as follows:

$\beta_{0}=\lambda \gamma_{0}$

$\beta_{2}=\lambda \gamma_{1}$

$\beta_{1}=(1-\lambda)$

In this case, $\lambda$ measures the speed of adjustment, and should logically lie in the interval between 0 (no adjustment at all) and 1 (full adjustment in the current period). The closer $\lambda$ is to 1 , the faster the speed of adjustment towards the target.

\subsection{The dynamic linear and partial adjustment model estimators}

According to Baltagi (2008:147), Elsas and Florysiak (2013:3), Flannery and Hankins (2013:3) and Pian et al. (2009:667), the possible statistical errors of the partial adjustment model derive from the following:

1. There is heterogeneity amongst individuals.

2. There is autocorrelation due to the presence of the lagged dependent variable. The lagged explanatory variable is correlated with the error term.

3. Market-to-debt ratios are fractional in nature; thus they are bounded between 0 and 1 .

4. The efficiency of the estimator is affected by the size and balance of the panel. In corporate finance research, the panel is usually unbalanced and very small. Typically, the panels are of the types "large $\mathrm{N}$ and short T" with $\mathrm{N} \geq 100$ and $\mathrm{T} \leq 30$.

A suitable estimator should be capable of yielding unbiased estimates of the parameters of the model in the presence of all these possible errors. Finding an unbiased, consistent and efficient estimator for the partial adjustment model has been a challenge for financial economists. A number of estimators have been developed, but these vary in terms of their degree of bias, as well as their consistency and efficiency. The most common types of estimators used in capital structure research include the ordinary least squares (OLS) regression; fixed effects estimator; random effects estimator; between effects estimator; first-differenced instrumental variables estimator; the LSDVC estimator; the difference GMM estimator; the system GMM estimator and the random effects Tobit estimator.

From the simple dynamic panel data model, $y_{i, t+1}=f\left(\mu_{i}\right)$, it follows that $y_{i, t}=f\left(\mu_{i}\right)$. This relationship implies that $y_{i, t}$ is therefore correlated with the error term. The correlation between $y_{i, t}$ and the error term renders the $\mathrm{OLS}$ a biased and inconsistent estimator, even if the term $v_{i, t+1}$ are not serially correlated (Baltagi, 2008:15). There is no transformation of the OLS that can reduce or eliminate this bias. The OLS estimator therefore has limited application in dynamic panel data models, and it was thus excluded from this study.

In the case of the fixed effects or within-group estimator (also called the least squares dummy variable (LSDV) estimator), Nickell (1981:1425) found that although the within transformation 
(fixed effects transformation) does eliminate the unobservable individual effect, it does not completely eliminate estimator bias. The within transformation process is described as follows. According to Baum (2006:221) and Baltagi (2008:15), the general regression model is stated as:

$$
y_{i, t}=x_{i, t} \beta_{k}+z_{i, t} \delta+v_{i}+\epsilon_{i, t+1} \quad i=1, \ldots, N \quad t=1, \ldots, T_{i}
$$

Averaging all the variables gives: $\bar{y}_{l}=(1 / T) \sum_{t=1}^{T} y_{i, t}, \quad \bar{x}_{l}=(1 / T) \sum_{t=1}^{T} x_{i, t}$ and $\bar{\varepsilon}_{l}=$ $(1 / T) \sum_{t=1}^{T} \varepsilon_{i, t}$. The terms $x_{i, t}$ and $x_{i, t}$ also depict panel-level averages. Subtracting these from the first equation gives:

$$
y_{i, t}-\bar{y}_{l}=\left(x_{i, t}-x_{i}\right) \beta+\left(z_{i}-z_{i}\right) \delta+v_{i}-\bar{v}_{l}+\epsilon_{i, t}-\bar{\varepsilon}_{l}
$$

The within transformed equation is:

$$
\widetilde{y_{l, t}}=\left(\widetilde{x_{l, t}}\right) \beta+\widetilde{\varepsilon_{l, t}}
$$

It should be noted that $\widetilde{y_{l, t}}=y_{i, t}-\overline{y_{l}}$ is the time-demeaned data on $y$, and is similar for $\widetilde{x_{l, t}}$ and $\widetilde{\varepsilon_{l, t}}$. Thus the within transformation removes the unobservable individual specific effect, $\mu_{i}$, but $\left(y_{i, t}-\overline{y_{l .-1}}\right)$ is still correlated with $\left(v_{i, t}-\bar{v}_{l .}\right)$, even if the $v_{i, t}$ is not serially correlated.

The within estimator is inconsistent for large $\mathrm{N}$ and short $\mathrm{T}$. It is, however, consistent for large $\mathrm{N}$ and short T, provided that both $T \rightarrow \infty$ and $N \rightarrow \infty$. Judson and Owen (1999:13) found that the within estimator has a bias of up to $20 \%$ for $T=30$. This therefore renders the estimator inconsistent and biased for capital structure research where $T$ is typically $T<30$.

The nature of the partial adjustment model also renders the random effects GLS estimator biased. This bias can, however, be eliminated by performing either quasi-demeaning or first-differencing transformation. According to Anderson and Hsiao (1981:603), the estimator can initially be firstdifferenced to eliminate $\mu_{i}$. The general dynamic panel data model that excludes the other exogenous covariates can be stated as:

$$
y_{i, t}=\beta y_{i, t-1}+\mu_{i}+u_{i, t} \quad i=1, \ldots, N \quad t=1, \ldots, T
$$

First-differencing this equation yields:

$$
y_{i, t}-y_{i, t-1}=\beta\left(y_{i, t-1}-y_{i, t-2}\right)+u_{i, t}-u_{i, t-1}
$$

The first-differenced model that includes exogenous variables will be stated as:

$$
y_{i, t}-y_{i, t-1}=\beta\left(y_{i, t-1}-y_{i, t-2}\right)+\beta_{2}\left(x_{i, t}-x_{i, t-1}\right)+u_{i, t}-u_{i, t-1}
$$

From the above, $y_{i, t-1}-y_{i, t-2}$ will be correlated with $u_{i, t}-u_{i, t-1}$, since $y_{i, t-1}$ is correlated with $u_{i, t-1}$. Use of instrumental variables eliminates this problem. Furthermore, $\Delta y_{i, t-2}=\left(y_{i, t-2}-\right.$ $\left.y_{i, t-3}\right)$ or $y_{i, t-2}$ can be used as an additional instrument for $\Delta y_{i, t-1}=\left(y_{i, t-1}-y_{i, t-2}\right)$. Arellano and Bond (1991:279) recommend the use of $y_{i, t-2}$ as an instrumental variable. This transformation yields a first-differenced instrumental variables (IV) estimator whose instruments are not correlated with $\Delta v_{i, t}=v_{i, t}-v_{i, t-1}$, as long as the $v_{i, t}$ factors themselves are not serially correlated. The estimator is stated as:

$$
\widehat{\beta_{I V}}=\frac{\sum_{i=1}^{N} \sum_{t=3}^{T}\left(y_{i, t}-y_{i, t-1}\right)\left(y_{i, t-2}-y_{i, t-3}\right)}{\sum_{i=1}^{N} \sum_{t=3}^{T}\left(y_{i, t}-y_{i, t-1}\right)\left(y_{i, t-2}-y_{i, t-3}\right)}
$$

This estimator assumes that the covariates in $x_{i, t}$ are strictly exogenous, and therefore $x_{i, t}-$ $x_{i, t-1}$ serve as instruments. This estimator is consistent when $N \rightarrow \infty$ or $T \rightarrow \infty$, or both. The 
process of within transformation and first-differencing/quasi-demeaning yields the IV or error components/correction estimators. The main variants of these estimators are the GLS random effects estimator, the fixed effects estimator, the between effects estimators, and the firstdifferenced estimator. These variants are two-stage least squares generalisations of panel data estimators. The first-differenced estimators assume that a subset of explanatory variables is correlated with the idiosyncratic error, $\varepsilon_{i, t+1}$. Ahn and Schmidt (1995), however, found that the instrumental variables estimator leads to consistent but inefficient estimates of the parameters, as it does not use all the available moments. The instrumental variables estimator also neglects the differenced structure of the residual disturbances.

To improve the efficiency of the Anderson and Hsiao (1981) instrumental variables estimator, Arellano and Bond (1991) proposed a first-differenced generalised method of moments (GMM) estimator. This estimator, which builds on the works of Hansen (1982) and Holtz-Eakin, Newey and Rosen (1988), makes use of additional instruments obtained from the utilisation of orthogonality conditions that exist between the lagged values of $y_{i, t}$ and the disturbance $v_{i, t}$. These additional instruments include suitable lags of the levels of endogenous variables, strictly exogenous explanatory variables and any other variables that may be specified in the model. The resulting estimator is called the difference GMM estimator, and it has one-step and two-step variants. According to Qian et al. (2009:669), the two-step first-differenced GMM estimator allows for heteroskedasticity across firms. The two-step variant of the model is, however, unsuitable for small panels, as standard errors produced tend to be biased downwards (Blundell \& Bond, 1998:138). The distinct advantage of the dynamic panel data GMM estimators in capital structure research is that they have the potential to yield consistent parameter estimates in the presence of predetermined and endogenous right-hand side variables (Pian et al., 2009:669). Covariates need not be strictly exogenous. The main weakness of the difference GMM is that the lagged levels are often weak instruments for first-differenced variables. In particular, the estimator can perform poorly if the autoregressive parameters or the ratio of the variance of the panel-level effect to the variance of idiosyncratic error are too large. According to Blundell and Bond (1998:138), highly persistent data may cause both the IV and the difference GMM estimators to suffer severe small-sample bias due to weak instruments (Bruno, 2005b:473). Verbeek (2012:409) found that the difference GMM estimator is not robust in the presence of serial correlation; this renders it still biased.

The system GMM estimator proposed by Arellano and Bover (1995) and Blundell and Bond (1998) addresses the weaknesses of the difference GMM estimator by utilising both lagged levels and lagged differences as additional instruments. Like the difference GMM, the system GMM has onestep and two-step variants.

In summary, both the difference GMM and system GMM estimators are designed for small T, large $\mathrm{N}$ unbalanced panels; linear and dynamic models with independent variables that are not strictly exogenous; fixed individual effects; and heteroskedasticity and autocorrelation within individuals but not across them (Roodman, 2009:86). This means that some regressors may be endogenous and/or predetermined but not strictly exogenous. The estimators further require that there be no autocorrelation in the idiosyncratic errors across individuals.

The system GMM estimator of Blundell and Bond (1998) improves on the consistency, efficiency and bias of both the Anderson-Hsiao instrumental variables and the Arellano and Bond difference GMM estimators. It is therefore expected to be more consistent, more efficient and less biased than these two estimators. The estimates of the system GMM estimator are therefore expected to be closer to those of the random effects Tobit estimator discussed below. 
Bruno (2005b:474) observed that the IV, difference GMM and system GMM estimators work very well when $\mathrm{N}$ is large, but they yield severely biased and imprecise parameters in cases where the number of units is small ( $\mathrm{N}=10$ or 20 units). As a solution to this short panel bias, Kiviet (1995) and Bun and Kiviet (2003) propose an LSDVC estimator that is suitable for balanced dynamic panel data with small N and strictly exogenous covariates. Bruno (2005a:365) extends this estimator to cover unbalanced panels. The new estimator is called the bias-corrected LSDV (LSDVC) estimator, which uses any of the following estimators to initialise bias correction: the Anderson-Hsiao instrumental variables estimator, the Arellano and Bond (1991) estimator or the Blundell and Bond (1998) estimator. The Monte Carlo simulation results, together with the results of Flannery and Hankins (2013) study, give the LSDVC an edge over the IV, difference GMM and system GMM estimators. The LSDVC estimator does not improve the consistency and efficiency of the Anderson-Hsiao instrumental variables and the difference and system GMM estimators. It only uses these estimators as in-built options in addressing the bias of the LSDV estimator and thus its estimates are expected to be in line with those of the individual estimator option.

Leverage ratios are fractional in nature; they occur between 0 and 1 . This property of leverage ratios renders the difference GMM, system GMM, linear dynamic panel data and instrumental variables estimators biased in the context of unbalanced dynamic panel data with a fractional dependent variable. These estimators all ignore the fractional nature of the dependent variable. The most suitable estimator for this type of data is the random effects Tobit maximum likelihood (ML) estimator proposed by Tobin (1958). This estimator is unbiased in the presence of heterogeneity amongst individuals, and it is consistent in the context of unbalanced dynamic panel data with a fractional dependent variable. It is an equivalent of the double-censored dynamic panel data with a fractional dependent variable (DPF) estimator proposed by Elsas and Florysiak (2011:186) and Elsas and Florysiak (2013:1). According to Loudermilk (2007:463), the leverage $\left(\operatorname{Lev}_{i, t}\right)$ two-limit or doubly censored Tobit model that allows for two corner solution outcomes, 0 (minimum) and 1 (maximum), is expressed in terms of the latent leverage variable, $\left(\operatorname{Lev}_{i, t+1}^{*}\right)$ :

$$
\begin{gathered}
L e v_{i, t+1}^{*}=\gamma \boldsymbol{X}_{i, t+1}+g\left(\operatorname{Lev}_{i, t}\right) \rho+\mu_{i}+u_{i, t+1} \\
u_{i, t+1} \mid\left(X_{i}, \operatorname{Lev}_{i, t}, \ldots, y_{i 0}, c_{i}\right) \sim N\left(0, \sigma_{u}^{2}\right) \\
L e v_{i t+1}=\left\{\begin{array}{cc}
0 & \text { if } L e v_{i, t+1}^{*} \leq 0 \\
L e v_{i t+1}^{*} & \text { if } 0<\operatorname{Lev}_{i, t+1}^{*}<1 \\
1 & \text { if } \operatorname{Lev}_{i, t+1}^{*} \geq 1 .
\end{array}\right.
\end{gathered}
$$

where $\operatorname{Lev}_{i, t}$ is the firm's leverage measured by that market-to-debt ratio $\left(M D R_{i, t}\right), \boldsymbol{X}_{i, t+1}$ is made up of strictly exogenous covariates, $\mu_{i}$ denotes the time-invariant unobservable individual effects, and $u_{i, t+1}$ is a normally distributed error term. As the random effects Tobit estimator takes into account the fractional nature of the market-to-debt ratio, it is therefore expected to be the most efficient and least biased estimator for the leverage partial adjustment model. 


\section{DATA SOURCES AND RESEARCH METHODOLOGY}

\subsection{Data}

The study used seven unbalanced panel data sets constructed from a sample of $143 \mathrm{JSE}$-listed non-financial firms with complete data for eight or more consecutive years during 2003 to 2012. All the financial data for the sampled firms was obtained from McGregor BFA's standardised annual financial statements. The samples were defined as follows: the full sample covered the years 2003-2012 and had a total of 1430 observations; the subsamples covered the year intervals 2003-2007, 2004-2008, 2005-2009, 2006-2010, 2007-2011 and 2008-2012, and each subsample had a total of 715 observations.

\subsection{The market-to-debt partial adjustment model}

Elsas and Florysiak (2013:8), Flannery and Hankins (2013:2), Flannery and Rangan (2006:472), Hovakimian and Li (2011:35), Hovakimian and Li (2012:736) and Zhou, Faff and Alpert (2014:496) derive the firm's target leverage partial adjustment model as follows:

Firstly, the firm's target market-to-debt ratio, $M D R_{i, t+1}^{*}$, is given by:

$$
M D R_{i, t+1}^{*}=\boldsymbol{X}_{i, t} \gamma
$$

where $\boldsymbol{X}_{i, t}$ is a vector of firm characteristics that determine target leverage and the speed of adjustment towards target leverage, $\gamma$ is a coefficient vector. Secondly, the firm's leverage partial adjustment model is specified as:

$$
M D R_{i, t+1}-M D R_{i, t}=\left(M D R_{i, t+1}^{*}-M D R_{i, t}\right)+\varepsilon_{i, t+1}
$$

where $\varepsilon_{i, t+1}$ is an error term. Substituting (21) into (22) and simplifying the equation yields a one-step partial adjustment model that can be used to estimate the firm's speed of adjustment towards the target leverage, that is:

$$
M D R_{i, t+1}=(1-\lambda) M D R_{i, t}+\lambda\left(\boldsymbol{X}_{i, t} \gamma\right)+c_{i}+\varepsilon_{i, t+1}
$$

where $\lambda$ denotes the speed of adjustment (SOA) towards the target leverage, and $c_{i}$ is the timeinvariant unobserved variable (firm-fixed effect). For the dynamic trade-off theory hypothesis to hold, there have to be some elements of the coefficient vector that are different from zero, that is, $\gamma \neq 0$. In cases where $\lambda=0$, it means that the SOA is zero, implying that firms have no target leverage ratios. If $\lambda=1$, it means that the firm immediately adjusts towards its target debt ratio. It is also possible to get negative values of $\lambda$. A negative SOA means that the firm overadjusts its leverage (Qian et al., 2009:664).

In order to compare the consistency, bias and efficiency of the leading dynamic panel data estimators, the SOA of the two panel data samples were estimated using the Arellano-Hsiao instrumental variables, LSDVC, difference GMM, system GMM and random effects Tobit estimators. The Hausman (1978) test was used to test for the consistency of the random and fixed effects variants of the Arellano-Hsiao instrumental variables estimator. In the instrumental variables estimator, the further lags $M D R_{i, t-1}, M D R_{i, t-2}, M D R_{i, t-3}, \ldots$ (for each $t$ ) were used as instruments for $M D R_{i, t}$. According to Verbeek (2012:409), the instrument $\triangle M D R_{i, t-2}$ is irrelevant, and thus it was not used in this study. The Anderson-Hsiao instrumental variables estimator, the Arellano and Bond (1991) estimator, and the Blundell and Bond (1998) estimator were each used 
to initialise bias correction in the LSDVC estimator. The study used the one-step and two-step difference and system GMM estimators, and the Sargan (1958) test was used to test the validity of the over-identifying restrictions of both estimators. In the cases of both of the GMM estimators, the study also tested for first-order and second-order autocorrelation. The robust standard error type option was used to control for heteroskedasticity in the one-step and two-step difference and system GMM estimators. Other estimators do not have the robust option for standard errors. The Gauss-Hermite quadrature integration option was used for the random effects Tobit estimator. Lastly, the confidence level of estimation was set at $95 \%$ for all the estimators. All tests were done on Stata 12.

\subsection{Test hypothesis}

This study tests for the consistency and efficiency of the leading partial adjustment model estimators. These estimators are the LSDVC estimator, the difference GMM estimator, the system GMM estimator and the random effects Tobit estimator. The estimators were used to estimate the target SOA of seven different panel datasets drawn from a sample of 143 non-financial companies listed on the JSE during the period 2003-2012. The hypotheses of the study are stated as follows:

Hypothesis 1: The random effects Tobit estimator, the LSDVC estimator and the system GMM estimator should yield similar estimates of the target SOAs.

Hypothesis 2: The target SOAs obtained using the random effects Tobit estimator and the system GMM estimator are significantly lower than those of the LSDVC estimator and the difference GMM estimator.

Hypothesis 3: The Anderson-Hsiao instrumental variables estimator and the difference GMM estimator suffer from the use of weak instruments, and should therefore yield SOA estimates that are upwards-biased.

\section{RESULTS}

\subsection{Summary statistics}

The summary statistics of the sample are presented in TABLE 1 .

The mean leverage ratio of 0.1716 with a standard deviation of $20.37 \%$, as found in the JSE-listed non-financial firms, is lower in relation to the mean leverage ratio of 0.2682 with a standard deviation of $24.96 \%$, as found in the Compustat firms studied by Elsas and Florysiak (2011:191). This implies that, generally, JSE-listed firms have lower and less volatile market-debt ratios than the Compustat firms. The JSE-listed firms are more profitable (with a mean of 0.2000 ), have higher asset tangibilities (with a mean of 0.3240 ) and lower growth rates (with a mean market-to-book ratio of 1.3374), but are much smaller (with a mean size of 14.3066) than the Compustat firms (which have a mean profitability of 0.0036 , a mean asset tangibility of 0.3089 , a mean marketto-book ratio of 1.6855, and a mean size of 23.0928). According to Drobetz and Wanzenried (2006:948), firms with higher profitability, higher asset tangibility and lower growth rates have higher SOAs. Therefore, the JSE-listed firms are expected to have higher SOAs than their Compustat counterparts.

The data sample consists of $143 \mathrm{JSE}$-listed non-financial firms with complete data for eight or more consecutive years during the period 2003 to 2012 . The unbalanced panel was constructed 
from data drawn from standardised annual financial statements, which were obtained from the McGregor BFA database. The total number of observations for the period is 1,430 . To eliminate outlier observations and the most extremely mis-recorded data, all variables were winsorised at the $1^{\text {st }}$ and $99^{\text {th }}$ percentile.

Market-to-debt ratio (MDR): the total debt scaled up by the sum of the total debt and the firm market capitalisation.

Firm profitability (Profitability): earnings before interest, tax, depreciation and amortisation (EBITDA) as a fraction of total assets (TA).

Firm size (Size): the natural logarithm of total assets.

Asset tangibility (Tangibility): the fixed assets scaled up by the total assets.

Un-weighted market-to-book ratio (MTB): the sum of the market value of equity, the book value of preference shares and the book value of total debt, less deferred taxes; this is scaled up by the total assets.

TABLE 1: Full Sample Summary Statistics 2003-2012

\begin{tabular}{lrrrrrrrr}
\hline \multicolumn{1}{c}{ Variable } & No. & Mean & Median & $\begin{array}{c}\text { Std. } \\
\text { Dev. }\end{array}$ & Min. & Max. & $\begin{array}{c}\text { Skewne } \\
\text { ss }\end{array}$ & $\begin{array}{c}\text { Kurtosi } \\
\text { Obs. }\end{array}$ \\
\hline MDR & 1277 & 0.1716 & 0.0940 & 0.2037 & 0.0000 & 0.9138 & 1.5880 & 5.4508 \\
\hline Profitability & 1430 & 0.2000 & 0.1944 & 0.1186 & 0.0193 & 0.4023 & 0.1693 & 2.0518 \\
Size & 1430 & 14.3066 & 14.4855 & 2.0317 & 10.8046 & 17.2895 & -0.2129 & 1.9738 \\
\hline Tangibility & 1430 & 0.3240 & 0.2921 & 0.2278 & 0.0435 & 0.7104 & 0.3895 & 1.8283 \\
MTB & 1419 & 1.3374 & 1.0888 & 0.8422 & 0.3947 & 3.0554 & 0.8413 & 2.5400 \\
\hline
\end{tabular}

Source: Author's analysis

\subsection{Empirical Results}

\subsubsection{Full sample results $(T=10)$}

The estimates of the target SOAs and the number of observations, WaldChi2 and Prob > Chi2, together with the Sargan (1958) and the first order autoregressive process AR (1) and the second order autoregressive process AR (2) test statistics for the two samples, are contained in TABLE 2.

The Hausman (1978) test statistic, Chi2, is 291.19 and Prob > Chi2 is 0.0000 . This statistic soundly rejects the null hypothesis that the random estimator is consistent $(p<.05)$, and confirms the fixed effects model as a more consistent estimator in both cases. The individual effects appear to be correlated with the regressors. The extra orthogonality conditions imposed by the random estimator are invalid, and therefore the option of the Anderson-Hsiao IV random effects estimator was not used. The Hausman (1978) test only tests for the consistency of the random and fixed effects models; it is inapplicable to the other models used in this study. The secondorder serial correlation (AR (2)) test statistics of both the difference and system GMM estimators fail to reject the null hypothesis that there is no second-order autocorrelation in $\Delta u_{i, t+1}$ (Prob > Chi2 is $0.0000, p>.05$ ), and thus the models may not be misspecified. The Sargan (1958) test statistics, however, suggest rejecting the null hypothesis that all the instruments are valid 
(Prob>Chi2 is $0.0000, p<.05$ ). The models may suffer from the problem of over-identification, and therefore the speed of adjustment estimates produced by the difference and system GMM estimators may be inconsistent. The two-step Sargan (1958) test is, however, only valid in the presence of homoskedasticity and it tends to under-reject the validity of the over-identifying restrictions in the presence of heteroskedasticity (Arellano \& Bond, 1991:288). Thus the rejection may be attributed to heteroskedasticity in the data-generating process.

The two-stage system GMM's estimate of $45.40 \%$ (half-life of 1.15 years) is very close to the random effects Tobit estimator's estimate of $41.92 \%$ (half-life of 1.28 years). The system GMM's one-step parameter estimates are biased upwards, but all the one-step and two-step parameter estimates are robust in the presence of heteroskedasticity. These results validate hypothesis $l$.

The estimates yielded by the difference GMM estimator are biased upwards, confirming hypothesis 2. According to Blundell and Bond (1998), an upward bias may be due to the difference GMM estimator's weak instruments, and this is confirmed by the rejection of the null hypothesis under the Sargan (1958) test. The estimates of the LSDVC estimator are closer to those of the bias-error initialising estimator, thus confirming that the effectiveness of the estimator is due to bias correction, as suggested by Bruno (2005a). Lastly, the parameters of the Anderson-Hsiao instrumental variables' fixed effects and first-differenced estimators are severely biased upwards, whilst the between-effects estimator parameter is severely biased downwards. Ahn and Schmidt (1995) attribute a bias such as this to the estimator neglecting the differenced structure of the residual errors and failing to exploit all available instruments.

In summary, for a sample where $T=10$, the random effects Tobit estimator, the two-step system GMM estimator and the LSDVC estimator initialised by the system GMM estimator yield similar estimates for the target speed of adjustment. The balance of the estimators is inappropriate for this size of panel, as their parameters significantly deviate from those of the random effects Tobit estimator, the two-step system GMM estimator and the LSDVC estimator initialised by the system GMM estimator.

Regression results for the partial adjustment model:

$$
M D R_{i, t+1}=\lambda\left(\gamma \boldsymbol{X}_{i, t}\right)+(1-\lambda) M D R_{i, t}+c_{i}+\varepsilon_{i, t+1}
$$

Where $\lambda$ is the adjustment speed towards the target market-to-debt ratio, $\gamma$ is a coefficient vector, $\boldsymbol{X}_{i, t}$ is a vector of firm characteristics that determine target leverage and the speed of adjustment towards target leverage, $c_{i}$ is the time-invariant unobserved variable (firm fixed effect) and $\varepsilon_{i, t+1}$ is an error term. The vector $\boldsymbol{X}_{i, t}$ consists of the variables: profitability, size, tangibility and market-to-book ratio, and these are defined in TABLE 1 . T-statistics are reported

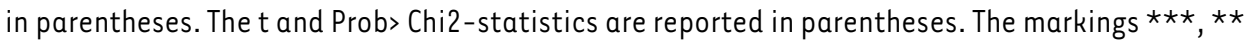
and $*$ denote coefficients that are statistically significantly different from zero at the levels of $1 \%, 5 \%$, and $10 \%$ respectively. The implied half-life is calculated as: half-life $=$ $\log (0.5) / \log (1-\lambda)$. The Hausman (1978) test statistic Chi2 is 183.40 and Prob>Chi2 is 0.0000 . The Sargan (1958), AR (1) and AR (2) test statistics are shown for both the Arellano \& Bond (1991) and the Blundell \& Bond (1998) estimators. 


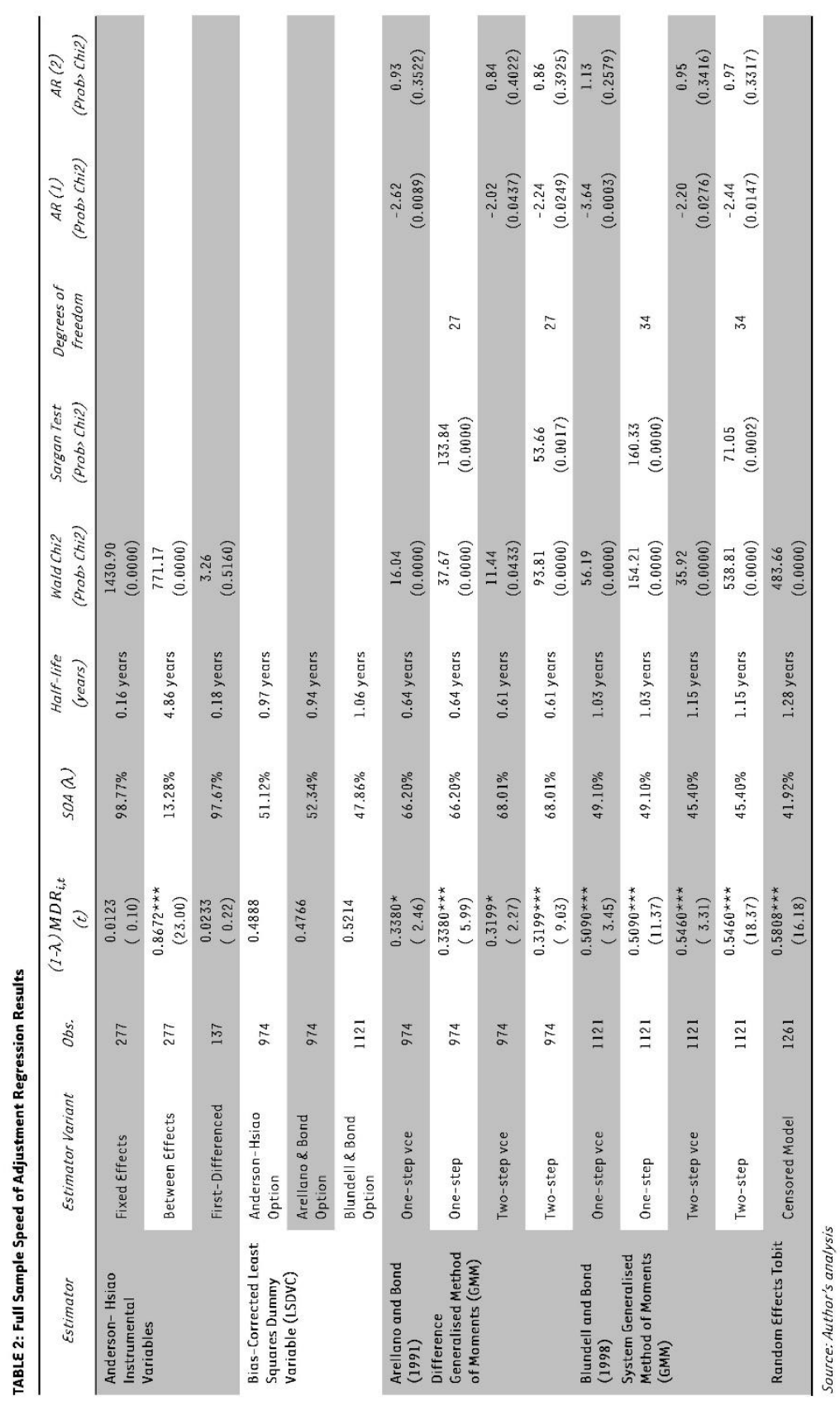




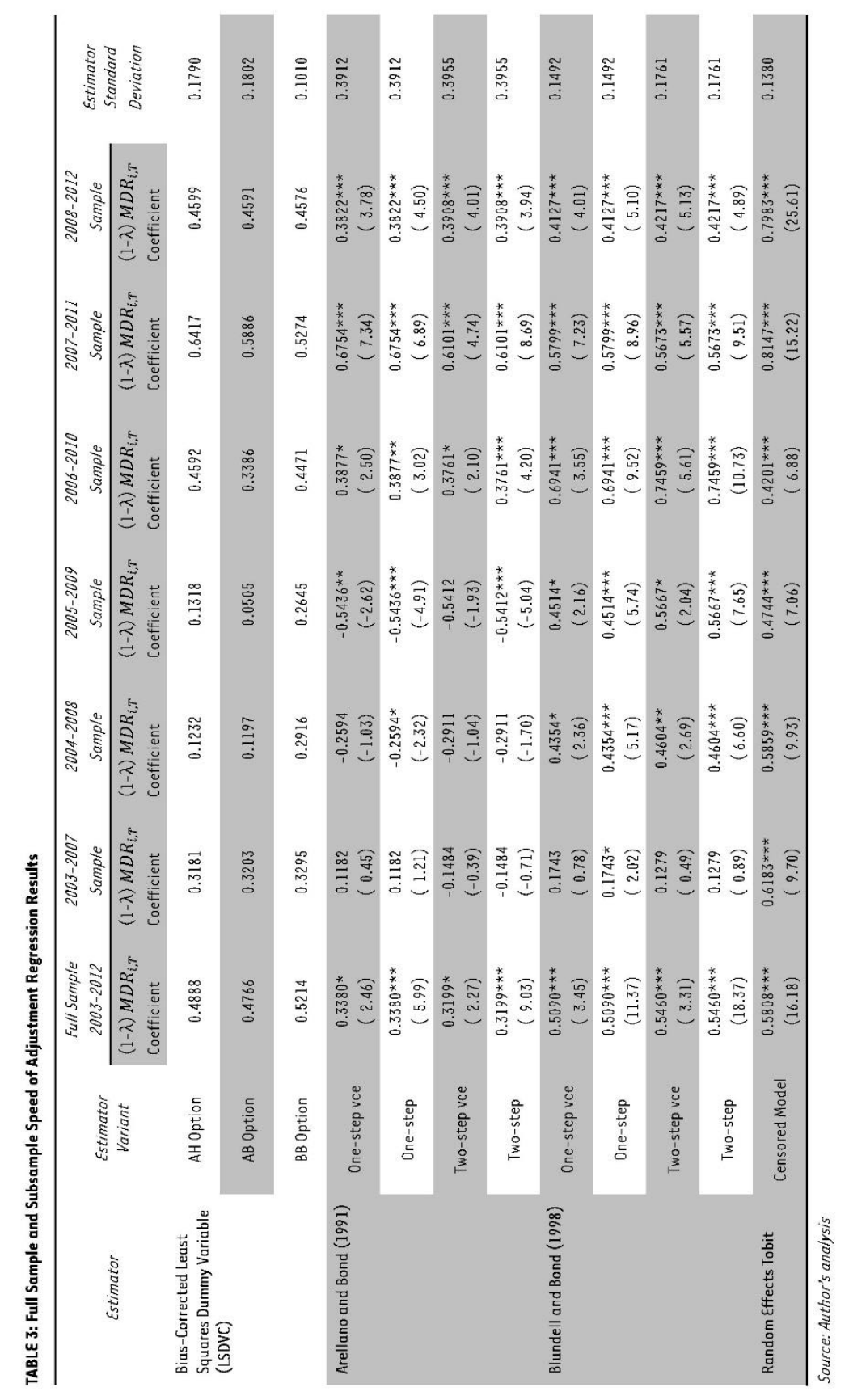


Regression results for the partial adjustment model:

$$
M D R_{i, t+1}=\lambda\left(\gamma \boldsymbol{X}_{i, t}\right)+(1-\lambda) M D R_{i, t}+c_{i}+\varepsilon_{i, t+1}
$$

Where $\lambda$ is the adjustment speed towards the target market-to-debt ratio, $\gamma$ is a coefficient vector, $\boldsymbol{X}_{i, t}$ is a vector of firm characteristics that determine target leverage and the speed of adjustment towards target leverage, $c_{i}$ is the time-invariant unobserved variable (firm fixed effect) and $\varepsilon_{i, T+1}$ is an error term. The vector $\boldsymbol{X}_{i, t}$ consists of the variables: profitability, size, tangibility and market-to-book ratio, and these are defined in TABLE 1 . The $t$ and Prob > Chi2statistics are reported in parentheses. The markings $* \star \star, * \star$ and $*$ denote coefficients that are statistically significantly different from zero at the levels of $1 \%, 5 \%$, and $10 \%$ respectively.

\subsubsection{Full sample and subsample results}

The results for the full sample and the subsamples are contained in TABLE 3 . In all the subsamples, the Anderson-Hsiao instrumental variables estimator yielded no parameter estimates for the partial adjustment model, and therefore it is not included in the table. This failure confirms the inefficiency and small-sample bias of the Anderson-Hsiao instrumental variables estimator when applied to shorter T panels. The LSDVC estimator with the bias correction initialised by the Blundell and Bond estimator has the lowest standard deviation (0.1010), and this renders it the most consistent estimator for the partial adjustment model. Bruno (2005a:365) and Flannery and Hankins (2013) documented similar findings when using Monte Carlo experiments. The random effects Tobit estimator ranks second, with a standard deviation of 0.1380 , and the one-step system GMM estimator ranks third, with a standard deviation of 0.1492 . The small standard deviations of these estimators confirm their consistency and robustness to the possible dynamic panel statistical errors of heteroskedasticity and serial correlation. Lastly, all the variants of the difference GMM estimator have the highest standard deviations, and this renders them inconsistent estimators for the partial adjustment model. The graphical comparisons of estimator standard deviations across the seven subsamples are contained in FIGURES 1 and 2.

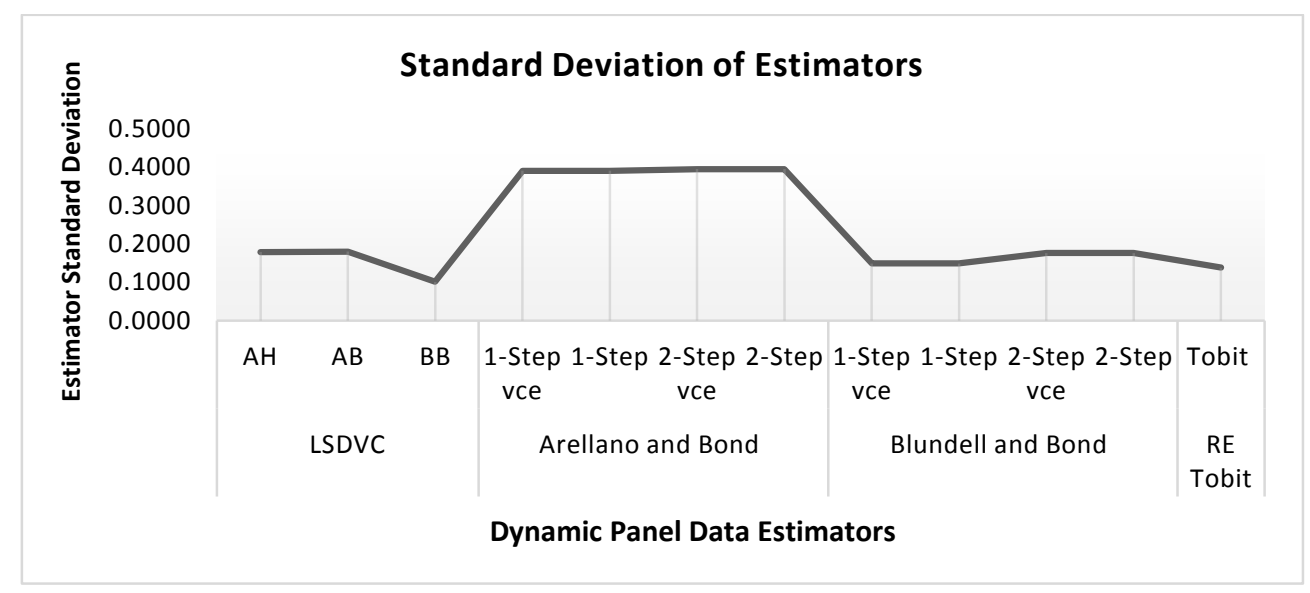

FIGURE 1: Line Graph of Estimator Performance with Varying Sample T 


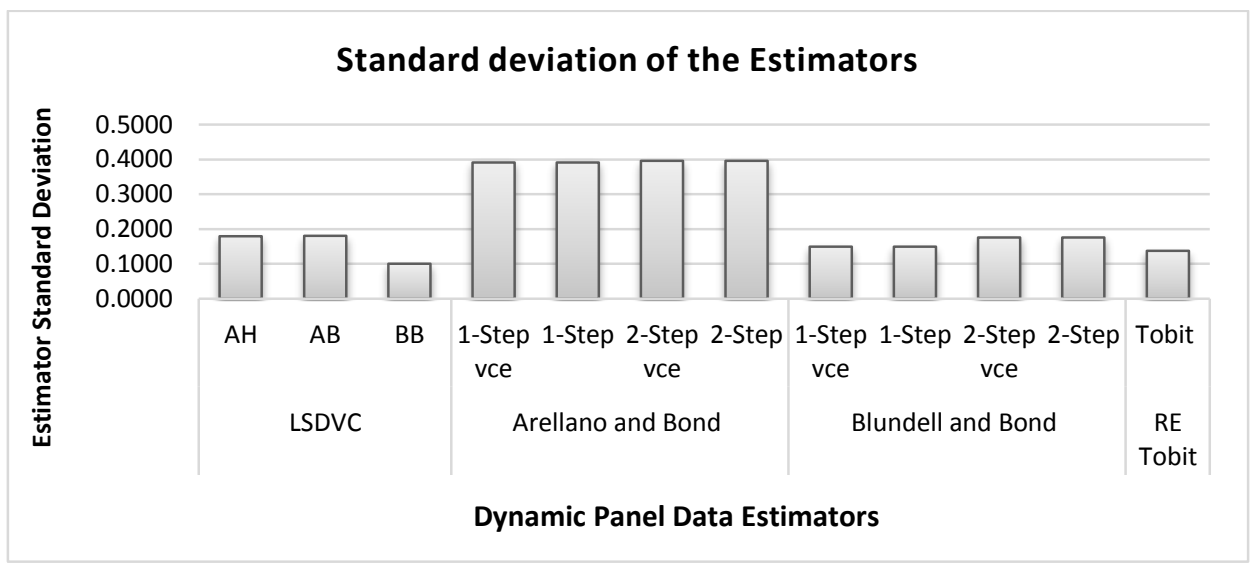

FIGURE 2: The Standard Deviation of the Partial Adjustment Model Estimators

\section{CONCLUSION}

This study tested for the consistency and estimation efficiency of the leading dynamic panel data estimators used in corporate finance research. These estimators are the random effects Tobit estimator, one-step and two-step system GMM estimators, one-step and two-step difference GMM estimators, the bias-corrected least squares dummy variable estimator and the AndersonHsiao instrumental variables estimator. The performance of the estimators is affected by the size of the panel. The Anderson-Hsiao IV estimator fails in small T samples. The LSDVC estimator with the bias correction initialised by the Blundell and Bond estimator, the random effects Tobit estimator and the one-step system GMM estimator have the lowest standard deviations across the seven subsamples used in the study. The low standard deviations confirm that these estimators are consistent and robust to the possible dynamic panel model statistical errors of heteroskedasticity and autocorrelation. The difference GMM estimator and the Anderson-Hsiao instrumental variables estimator exhibit very high standard deviations across the subsamples. This renders them biased, and therefore unsuitable for estimating the parameters of a linear dynamic panel data model with a fractional dependent variable. The most suitable estimators for this type of model are the LSDVC estimator initialised by the system GMM estimator, the random effects Tobit estimator and the system GMM estimator. The main limitation of the study is the limited specification tests for the random effects Tobit estimator. Future research work should be directed at devising specification tests for this model that will confirm the validity of the random effects Tobit estimator's parameters.

\section{LIST OF REFERENCES}

Ahn, S.C. \& Schmidt, P. (1995). Efficient estimation of models for dynamic panel data. Journal of Econometrics, 68(1), pp. 5-27.

Anderson, T.W. \& Hsiao, C. (1981). Estimation of dynamic models with error components. Journal of the American Statistical Association, 76(375), pp. 598-606. 
Antoniou, A., Guney, Y. \& Paudyal, K. (2008). The determinants of capital structure: capital market oriented versus bank oriented institutions. Journal of Financial and Quantitative Analysis, 43(1), pp. $59-92$.

Arellano, M. \& Bond, S. (1991). Some tests of specification for panel data: Monte Carlo evidence and an application to employment equations. Review of Economic Studies, 58(2), pp. 277-297.

Arellano, M. \& Bover, 0. (1995). Another look at the instrumental variables estimation of errorcomponents models. Journal of Econometrics, 68(1), pp. 29-51.

Auerbach, A. (1985). Real determinants of corporate leverage, the social science research. Available: http://www.nber.org/chapters/c11424.pdf (Accessed 25 June 2014).

Baltagi, B.H. (2008). Econometric Analysis of Panel Data, $4^{\text {th }}$ edition. Chichester, United Kingdom: John Wiley.

Blundell, R. \& Bond, S. (1998). Initial conditions and moment restrictions in dynamic panel data models. Journal of Econometrics, 87(1), pp. 115-143.

Bruno, G.S.F. (2005a). Approximating the bias of the LSDV estimator for dynamic unbalanced panel data models. Economics Letters, 87(3), pp. 361-366.

Bruno, G.S.F. (2005b). Estimation and inference in dynamic unbalanced panel-data models with a small number of individuals. The Stata Journal, 5(4), pp. 473-500.

Bun, M.J.G. \& Kiviet, J.F. (2003). On the diminishing returns of higher-order terms in asymptotic expansions of bias. Economics Letters, 79(2), pp. 145-152.

Chambers, M.J. (1996). Speed of adjustment and estimation of the partial adjustment model. Applied Economics Letters, 3(1), pp. 21-23.

Chen, L. \& Zhao, X. (2007). Mechanical mean reversion of leverage ratios. Economics Letters, 95(2), pp. 223-229.

Dang, V.N. (2013). Testing capital structure theories using the error correction models: evidence from the UK, France and Germany. Applied Economics, 45(2), pp. 171-190.

Drobetz, W. \& Wanzenried, G. (2006). What determines the speed of adjustment to the target capital structure? Applied Financial Economics, 16(13), pp. 941-958.

Elsas, R. \& Florysiak, D. (2011). Heterogeneity in the speed of adjustment toward target leverage. International Review of Finance, 11(2), pp. 181-211.

Elsas, R. \& Florysiak, D. (2013). Dynamic capital structure adjustment and the impact of fractional dependent variables. Working Paper, Institute of Finance and Banking, University of Munich, 1-44. Available: http://papers.ssrn.com/sol3/papers.cfm?abstract_id=1632362\#\# (Accessed: 25 June 2014).

Fama, E.F. \& French, K.R. (2002). Testing trade-off and pecking order predictions about dividends and debt. The Review of Financial Studies, 15(1), pp. 1-33.

Fischer, \&.O., Heinkel, R. \& Zechner, J. (1989). Dynamic capital structure choice: theory and tests. The Journal of Finance, 44(1), pp. 19-40.

Flannery, M.J. \& Hankins, K.W. (2013). Estimating dynamic panel models in corporate finance. Journal of Corporate Finance, 19, pp. 1-19.

Flannery, M.J. \& Rangan, K.P. (2006). Partial adjustment toward target capital structures. Journal of Financial Economics, 79(3), pp. 469-506. 
Frank, M.Z. \& Goyal, V.K. (2009). Capital structure decisions: which factors are reliably important? Financial Management, 38(1), pp. 1-37.

Hansen, L.P. (1982). Large sample properties of generalised method of moments estimators. Econometrica, 50(4), pp. 1029-1054.

Hausman, J.A. (1978). Specification tests in econometrics. Econometrica, 46(6), pp. 1251-1271.

Holtz-Eakin, D., Newey, W. \& Rosen, H.S. (1988). Estimating vector autoregressions with panel data. Econometrica, 56(6), pp. 1371-1395.

Hovakimian, A. \& Li, G. (2011). In search of conclusive evidence: how to test for adjustment to target capital structure. Journal of Corporate Finance, 17(1), pp. 33-44.

Hovakimian, A. \& Li, G. (2012). Is the partial adjustment model a useful tool for capital structure research? Review of Finance, 16(3), pp. 733-754.

Hovakimian, A., Opler, T. \& Titman, S. (2001). The debt-equity choice. Journal of Financial and Quantitative Analysis, 36(1), pp. 1-24.

Hovakimian, A., Opler, T. \& Titman, S. (2002). The capital structure choice: new evidence for a dynamic trade-off model. Journal of Applied Corporate Finance, 15(1), pp. 24-30.

Huang, R. \& Ritter, J.R. (2009). Testing theories of capital structure and estimating the speed of adjustment. Journal of Financial and Quantitative Analysis, 44(2), pp. 237-271.

Judson, R.A \& Owen, A.L. (1999). Estimating dynamic panel data models: a guide for macroeconomists. Economics Letters, 65(1), pp. 9-15.

Kiviet, J.F. (1995). On bias, inconsistency and efficiency of various estimators in dynamic panel data models. Journal of Econometrics, 68(1), pp. 53-78.

Leary, M.T. \& Roberts, M.R. (2005). Do firms rebalance their capital structures? The Journal of Finance, 60(6), pp. 2575-2619.

Loudermilk, M.E. (2007). Estimation of fractional dependent variables in dynamic panel data models with an application to firm dividend policy. Journal of Business \& Economic Statistics, 25(4), pp. 462472 .

Moyo, V., Wolmarans, H. \& Brümmer, L. (2013). Trade-off or pecking order hypothesis? Evidence from South African manufacturing, mining and retail firms. International Business \& Economics Research Journal, $12(8)$, pp. 927-944.

Mukherjee, S. \& Mahakud, J. (2012). Are trade-off and pecking order theories of capital structure mutually exclusive? Evidence from Indian manufacturing firms. Journal of Management Research, 12(1), pp. 41-55.

Nickell, S. (1981). Biases in dynamic models with fixed effects. Econometrica, 49(6), pp. 1417-1426.

Oztekin, 0.\& Flannery, M.J. (2012). Institutional determinants of capital structure adjustment speeds. Journal of Financial Economics, 103(1), pp. 88-112.

Qian, Y., Tian, Y. \& Wirjanto, T.S. (2009). Do Chinese publicly listed companies adjust their capital structure toward a target level? China Economic Review, 20(4), pp. 662-676.

Ramjee, A. \& Gwatidzo, T. (2012). Dynamics in capital structure determinants in South Africa. Meditari Accountancy Research, 20(1), pp. 52-67. 
Roodman, D. (2009). How to do xtabond2: an introduction to difference and system GMM in Stata. The Stata Journal, 9(1), pp. 86-136.

Sargan, J. (1958). The estimation of economic relationships using instrumental variables. Econometrica, 26(3), pp. 393-415.

Taggart Jnr, R.A. (1977). A model of corporate financing decisions. The Journal of Finance, 32(5), pp. 467-1484.

Tobin, J. (1958). Estimation of relationships for limited dependent variables. Econometrica, 26(1), pp. 24-36.

Verbeek, M. (2012). A Guide to Modern Econometrics, $4^{\text {th }}$ edition. Chichester, United Kingdom: John Wiley.

Xu, Z. (2007). Do firms adjust toward a target leverage level? Working Paper 2007-50, Bank of Canada, 1-48. Available: http://www.econstor.eu/bitstream/10419/53884/1/548044252.pdf (Accessed 25 June 2014).

Zhou, Q., Faff, R. \& Alpert, K. (2014). Bias correction in the estimation of dynamic panel models in corporate finance. Journal of Corporate Finance, 25, pp. 494-513. 